\title{
Correction to: Enhanced polyethylene glycol (PEG)-mediated protoplast transformation system for the phytopathogenic fungus, Ganoderma boninense
}

\author{
Fook-Hwa Lim ${ }^{1,2}$. Omar Abd Rasid ${ }^{1}$. Abu Seman Idris ${ }^{1}$ Abdul Wahab Mohd As' wad $^{2}$. Ganesan Vadamalai ${ }^{2,3}$. \\ Ghulam Kadir Ahmad Parveez ${ }^{1} \cdot$ Mui-Yun Wong ${ }^{2,3}$
}

Published online: 6 July 2021

(c) Institute of Microbiology, Academy of Sciences of the Czech Republic, v.v.i. 2021

\section{Correction to: Folia Microbiologica}

https://doi.org/10.1007/s12223-021-00852-6

The original version of the article unfortunately contained some errors.

There is a misspelling word in the abstract. The word "efirst" was replaced with "first".

The formula to determine the protoplast concentration was reorganized (page 3).

The Table 2 contents were rearranged.

The additional phrase "the incubation time of 40 minutes" in the reference section (Teh et al. 2019) was removed.
Publisher's Note Springer Nature remains neutral with regard to jurisdictional claims in published maps and institutional affiliations.

The original article can be found online at https://doi.org/10.1007/ s12223-021-00852-6.

Fook-Hwa Lim

fookhwa@mpob.gov.my

Mui-Yun Wong

muiyun@upm.edu.my

1 Malaysian Palm Oil Board, 6 Persiaran Institusi, Bandar Baru Bangi, 43000 Kajang, Selangor, Malaysia

2 Department of Plant Protection, Faculty of Agriculture, Universiti Putra Malaysia, 43400 UPM Serdang, Selangor, Malaysia

3 Institute of Plantation Studies, Universiti Putra Malaysia, 43400 UPM Serdang, Selangor, Malaysia 